\title{
Determination of Cable Tension Force using Accelerometer
}

\author{
Made Suangga, Rayner Gunawan, Irpan Hidayat
}

\begin{abstract}
Cable is the main element in a long span structure and is often used for special structures such as long span bridges, roofs and other structures that require a long span. The stiffness of the cable is determined by the amount of axial tensile force acting on the cable, and hence, the magnitude of the actual tensile force on the cable is an important factor to be determined and monitored. One simple method for determining the actual tensile force on a cable is to calculate the tensile force from the first natural frequency of the cable. However, it is important to ensure that the formulas used to calculate the tensile force are accurate.

This research aims to determine the level of accuracy and the factors that influence the accuracy of the formula to determine the tension force of the cable from the natural frequency value of the cable. The methodology used in this research project was by applying free vibrations to the cable with given axial tensile load and measuring the acceleration that occurred with an accelerometer sensor. By using Fast Fourier Transform (FFT), the natural frequency value of the cable can be calculated and the actual tensile strength in the cable can be determined.

From the experiment conducted, it was found that the length of the cable affects the accuracy of the measurement of the natural frequency and the magnitude of tensile force of the cable. The strain that occurs on the cable plays a very important role to the accuracy of the formulas used.
\end{abstract}

Keywords: accelerometer, cable, natural frequency, tension force.

\section{INTRODUCTION}

Cables are elements that are often used in building structures and bridges. Cables are widely used in the tied-arch bridges and suspension bridges as the major elements to transfer loads from the deck to the arch or pylon. The cable has a very unique characteristic where the stiffness of the cable is determined by the amount of axial tensile force acting on the cable.

Monitoring the structure's condition is an activity that must be conducted to ensure that the structure is in a safe condition. The monitoring process is carried out by measuring the stiffness of the structure. In the case of structures with cable elements, monitoring of the tensile forces in the cable needs to be done periodically, and if

Revised Manuscript Received on December 30, 2019.

* Correspondence Author

Made Suangga*, Civil Engineering Department, Bina Nusantara University, Jakarta, Indonesia.

Rayner Gunawan, Civil Engineering Department, Bina Nusantara University, Jakarta, Indonesia.

Irpan Hidayat, Civil Engineering Department, Bina Nusantara University, Jakarta, Indonesia.

(C) The Authors. Published by Blue Eyes Intelligence Engineering and Sciences Publication (BEIESP). This is an open access article under the CC BY-NC-ND license (http://creativecommons.org/licenses/by-nc-nd/4.0/) needed, in real time because the tensile forces in the cable determine the stiffness of the cable. The tension force of cables must be measured accurately because it is very important in assessing the structural conditions during construction and in-service stages [1] [2].

The method that is commonly used in determining the axial force on a cable is by installing sensors such as Electromagnetic (EM) sensors, load cells or by conducting dynamic tests using an accelerometer. Measurement with dynamic tests is often preferred because it is easy and economical to do. The data from the dynamic test using accelerometer sensors are then processed by Fast Fourier Transform (FFT) to get natural frequencies of the cable structure. Based on the natural frequency value, the tension force of the cable can be calculated theoretically [3] [4].

Currently, the available techniques to estimate the cable tension are the static methods which directly measuring the tension by a load cell and the vibration methods which indirectly estimating the tension force from measured natural frequencies value [5] [6]. Due to the simplicity of application and the high accuracy of this method, the identification of cable force based on the vibration method has been widely used and has become popular in engineering practice [5] [6].

Problems that occur in determining the amount of tension force of the cable are related to the level of accuracy of the formula used. There are several factors that are thought to be the cause of calculation inaccuracy, including the curvature of the cable, the effective length of the cable, and the condition of the location of the cable.

This research aims to determine the accuracy of the formula used to determine the magnitude of the cable force based on the natural frequency value of the cable to obtain a better understanding of the level of accuracy of the formula for determining the tensile force in the cable.

\section{METHODOLOGY}

The purpose of this research is to determine the level of consistency of the cable force formula obtained from natural frequencies of the cable which is measured using accelerometer. The methodology of this research is presented bellow

a. The top end of the cable is held by anchorage steel plate to the wall and the bottom end of the cable which holding the hanging load is resting on adjustable steel frame.

b. Cable with diameter of $6 \mathrm{~mm}$ and $8 \mathrm{~mm}$ are used in this experiment

c. The experiment is conducted for different load magnitude or cable tension and different cable inclination 
d. The characterizing of the cable is determined including cable diameter, modulus of elasticity, and slenderness.

e. Finite element model of the cable has been developed for dynamic analysis to calculate the natural frequency.

f. The free vibration of the cable was recorded using accelerometer sensor and the data recorded from accelerometer sensor then analyzed using Fast Fourier Transform (FFT) to obtain the natural frequencies of the cable

g. The natural frequency of the cable from FFT is used to determine the theoretical tension force of the cable and then compared with the actual force.

h. The consistency of the test result is investigated by the experimental with different impact location point, different examiners and also different cable inclination.

\section{PRACTICAL FORMULA TO DETERMINE CABLE FORCE FROM NATURAL FREQUENCY VALUE}

Many dynamic methodologies have been developed by considering the dynamic characteristics and physical properties of cables to estimate the tensile force for the cables. The difference present between the methodologies is depending on the consideration of the formula to cable sag and flexural rigidity.

\section{A. Flat Taut String Theory}

The flat taut string theory for cables neglects both sag-extensibility and flexural rigidity. The application of this formula is strictly limited to a flat long slender cable [4] [7].

The relationship between tension force and the natural frequency is as follow:

$$
\mathrm{T}=4 m L^{2}\left(\frac{f_{n}}{n}\right)^{2}
$$

Where $f_{n}$ denotes the $n^{\text {th }}$ natural frequency in $\mathrm{Hz}$. The terms $\mathrm{T}, \mathrm{m}$, and $\mathrm{L}$ denote tension force, mass density, and length of cable, respectively.

\section{B. Axially Loaded Beam Theory}

Based on the vibration equation of an axially loaded beam of both hinge ends. The formula which considers the bending stiffness but neglects the sag-extensibility is as follow [2] [3].

$$
T=4 m L^{2}\left(\frac{f_{n}}{n}\right)^{2}-\frac{E I \pi^{2} n^{2}}{L^{2}}
$$

Where EI denotes the flexural rigidity of a cable.

\section{The Practical Formula}

This practical formula included the bending stiffness of the cable however the sag effect is neglected for simplicity by using the frequencies relative to anti symmetric or higher vibration modes of the cable. The formula assumes that the ends of cable are both fixed [3].

$T=4 \pi^{2} m L^{2}\left(\frac{f_{n}}{\gamma_{n}}\right)^{2}-\frac{E I}{L^{2}} \gamma_{n}^{2}$

Where

$\gamma_{n}=n \pi+A_{n} \sqrt{\frac{E I}{m \omega_{n}^{2} l^{4}}}+B_{n} \frac{E I}{m \omega_{n}^{2} l^{4}}$
$A_{n}=-18.9+26.2 n+15.1 n^{2}$

$B_{n}=\left\{\begin{array}{cc}290, & n=1 \\ 0, & n \geq 2\end{array}\right.$

\section{EXPERIMENT SET-UP}

The setup of the experiment is described as follow

a. The top end of the cable is held by anchorage steel plate to the wall

b. The bottom end of the cable is holding the hanging load and the cable resting on adjustable steel frame.

c. The length of the cable is $1.41 \mathrm{~m}$

d. The variation of the inclination of cable are $60^{\circ}, 45^{\circ}$ and $30^{\circ}$

e. The variation of the tensile load at the bottom end of the cable are $50 \mathrm{~kg}, 70 \mathrm{~kg}$ and $100 \mathrm{~kg}$

f. The impact load was applied to the cable using hammer

g. The free vibration of the cable was recorded using accelerometer sensor

h. The data recorded from accelerometer sensor then analyzed using Fast Fourier Transform (FFT) to obtain the natural frequencies of the cable.

i. By using a theoretical formula the tensile force of the cable can be calculated and compared with the actual tensile load.

The cable parameter data for this experiment are as follow

a. d (cable diameter) : $6 \mathrm{~mm}$ and $8 \mathrm{~mm}$;

b. $\mathrm{m}$ (cable $\varnothing 6$ mass) : $1,82 \times 10-4 \mathrm{t} / \mathrm{m}$

c. $\mathrm{m}$ (cable $\varnothing 8$ mass) : 2,727 x 10-4 t/m

d. L (cable length) $: 1,41 \mathrm{~m}$

e. The slenderness of the cables are as presented in Table-I

Table-I: Parameter of the cables

\begin{tabular}{ccc}
\hline Parameter & Cable Ø6 & Cable Ø8 \\
\hline$\varnothing(\mathrm{m})$ & 0,006 & 0,008 \\
$\mathrm{~A}\left(\mathrm{~m}^{2}\right)$ & $2,82.10^{-5}$ & $5,03.10^{-5}$ \\
$\mathrm{~L}(\mathrm{~m})$ & 1,41 & 1,41 \\
$\mathrm{I}\left(\mathrm{m}^{4}\right)$ & $1,27.10^{-10}$ & $4,02.10^{-10}$ \\
$\mathrm{E}\left(\mathrm{kN} / \mathrm{m}^{2}\right)$ & $2.10^{-8}$ & $2.10^{-8}$ \\
$\rho\left(\mathrm{kN} / \mathrm{m}^{3}\right)$ & 78,5 & 78,5 \\
$\lambda$ & 664,68 & 498,51 \\
\hline
\end{tabular}

Table-II shows the variation of cable inclination and cable tensile load and Fig. 1 shows the experimental set up.

\begin{tabular}{|c|c|c|}
\hline No. & $\alpha\left(^{\circ}\right)$ & $\mathrm{P}(\mathrm{kN})$ \\
\hline 1 & \multirow{3}{*}{30} & 0,5 \\
\hline 2 & & 0,7 \\
\hline 3 & & 1,0 \\
\hline 4 & \multirow{3}{*}{45} & 0,5 \\
\hline 5 & & 0,7 \\
\hline 6 & & 1,0 \\
\hline 7 & \multirow{2}{*}{60} & 0,5 \\
\hline 8 & & 0,7 \\
\hline & $\begin{array}{l}\text { jence } \\
\text { cation }\end{array}$ & \\
\hline
\end{tabular}

Table-II: Variation of cable inclination and tensile load 


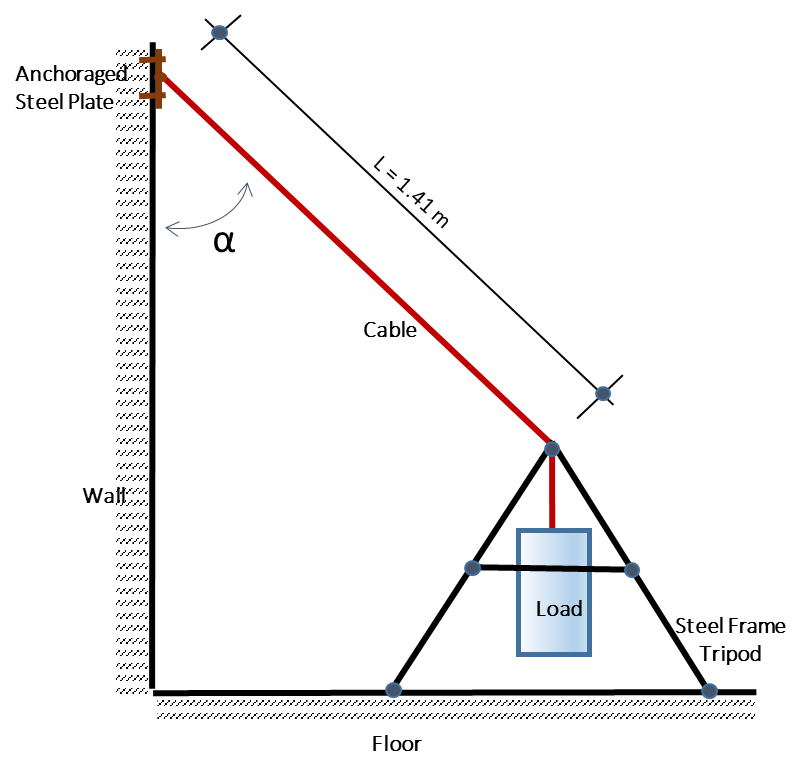

Fig. 1. Experiment set-up

\section{RESULT AND DISCUSSION}

\section{A. Finite Element Analysis of the Cable}

The finite element model of the cable has been developed and the dynamic analysis has been done for the cases considered. The first natural frequency based on finite element analysis of the cable element then compared with the natural frequency calculated using (1) and (2). The comparison between the cases are presented in Table-III and Table-IV.

Table-III: Comparison of the first natural frequency of cable with diameter of $6 \mathbf{m m}$.

\begin{tabular}{cccc}
\hline $\mathrm{P}(\mathrm{kN})$ & $\mathrm{f}_{1}(\mathrm{~Hz})$ & $\mathrm{f}_{1}(\mathrm{~Hz})$ & $\mathrm{f}_{1}(\mathrm{~Hz})$ \\
& $(1)$ & $(2)$ & $\mathrm{FEM}$ \\
\hline 0,5 & 20,843 & 18,588 & 18,56 \\
0,7 & 23,942 & 21,995 & 21,96 \\
1,0 & 27,954 & 26,285 & 26,247 \\
\hline
\end{tabular}

Table-IV: Comparison of the first natural frequency of cable with diameter of $8 \mathrm{~mm}$.

\begin{tabular}{cccc}
\hline $\mathrm{P}(\mathrm{kN})$ & $\mathrm{f}_{1}(\mathrm{~Hz})$ & $\mathrm{f}_{1}(\mathrm{~Hz})$ & $\mathrm{f}_{1}(\mathrm{~Hz})$ \\
& $(1)$ & $(2)$ & $\mathrm{FEM}$ \\
\hline 0,5 & 20,359 & 15,184 & 15,123 \\
0,7 & 22,51 & 17,965 & 17,895 \\
1,0 & 25,397 & 21,472 & 21,388 \\
\hline
\end{tabular}

From Table-III and Table-IV, it was found that the first natural frequency calculated using (2) has similar value with the first natural frequency from finite element analysis. This is because the cables are relatively short and therefore (2) could provide a more accurate result. For this research, (2) is used when calculating the theoretical first natural frequency of the cable.

\section{B. Effect of Impact Location to the First Natural Frequency}

Free vibration of the cable is excited by the impact of hammer applied to the cables. To investigate whether the the cable, impact load has been applied at two different locations, which are at the middle and at one quarter of the cable length. The result of Fast Fourier Transform of the impact location had significant effect to the first frequency of

accelerometer data at 2 impact load locations are presented in Fig. 2 and Fig. 3.

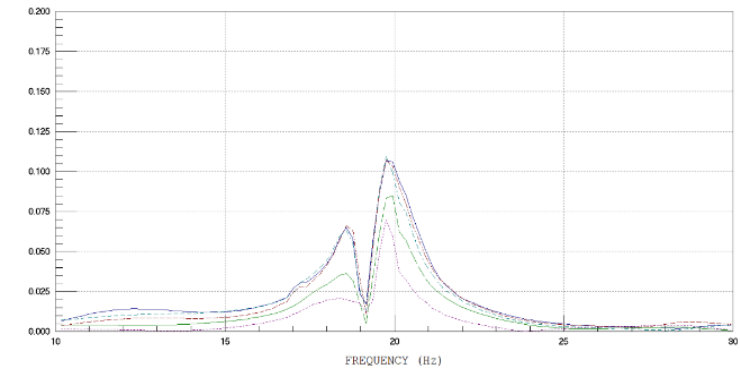

Fig. 2. Natural frequency in the middle of the cable span

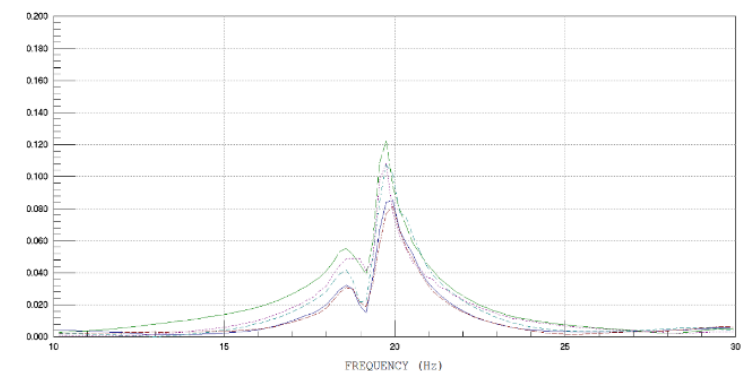

Fig. 3. Natural frequency in one quarter of the cable span

The average natural frequency for impact load at middle of the cable length, as shown in Fig. 5, is $18.59 \mathrm{~Hz}$, while the average natural frequency for impact load given at a quarter of cable span, as seen in Fig. 6, is $18.62 \mathrm{~Hz}$. From these results, it can be concluded that the impact location had no significant effect to the first frequency of the cable.

\section{Effect of Different Examiner to the First Natural Frequency}

This experimental was conducted to investigate the effect of different operators who conducted the dynamic test by comparing the first natural frequency value. Two examiners were assigned to give impact load to similar cable set up and using similar hammer. The result of Fast Fourier Transform of the accelerometer data from 2 different examiners are presented in Fig. 4 and Fig. 4 for Operator A and Operator B.

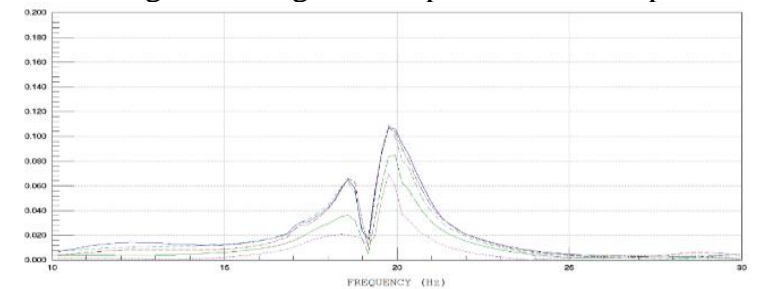

Fig. 4. Natural frequency with $50 \mathrm{~kg}$ load and Operator A

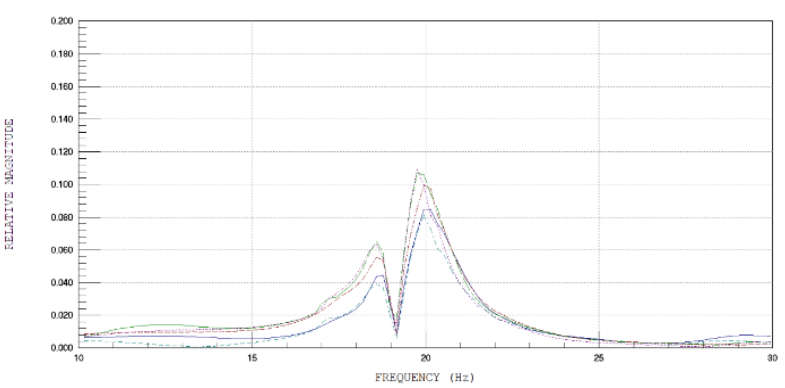

Fig. 5. Natural frequency with $50 \mathrm{~kg}$ load and Operator B

Published By: 
The average first natural frequency for impact load by Operator A as in Fig. 4 is $18.68 \mathrm{~Hz}$, while the average first natural frequency for impact load by Operator B as in Fig. 4 is $18.69 \mathrm{~Hz}$. It can be concluded that different operator has no significant effect to the first frequency of the cable.

\section{Effect of Cable Inclination to the First Natural Frequency}

The effect of cable inclination to the first natural frequency has been investigated by setting the inclination of the cable of $30^{\circ}, 45^{\circ}$ and $60^{\circ}$. The result of Fast Fourier Transforms of the accelerometer data at inclination of $30^{\circ}, 45^{\circ}$ and $60^{\circ}$ are presented in Fig. 6, Fig. 7 and Fig. 8, respectively.

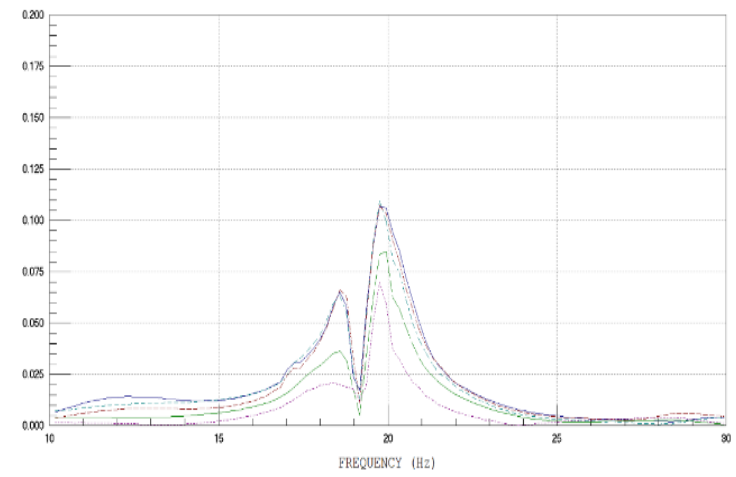

Fig. 6. Natural frequency with $50 \mathrm{~kg}$ load and $30^{\circ}$ angle

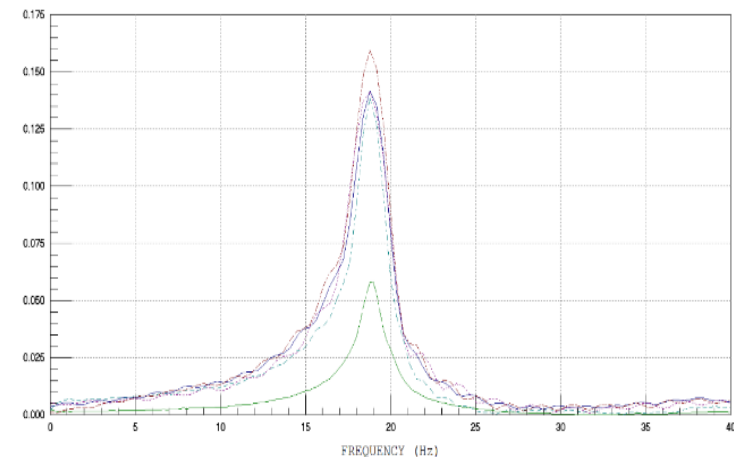

Fig. 7. The First Natural frequency with $50 \mathrm{~kg}$ load and $45^{\circ}$ angle

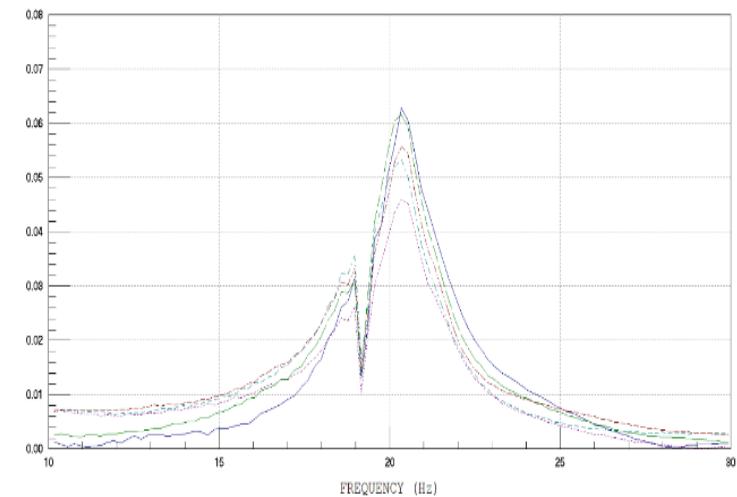

Fig. 8. The First Natural frequency with $50 \mathrm{~kg}$ load and $60^{\circ}$ angle

The average first natural frequency for cable with inclination of $30^{\circ}$ as in Fig. 6 is $18.59 \mathrm{~Hz}$, the average first natural frequency for cable with inclination of $45^{\circ}$ as in Fig. 7 is $18.61 \mathrm{~Hz}$ and the average first natural frequency for cable with inclination of $60^{\circ}$ as in Fig. 8 is $18.6 \mathrm{~Hz}$. Table-V and Table-VI shows the effect of cable inclination for different cable tension load and cable diameter.
It can be concluded that cable inclination has relatively small effect to the first natural frequency of the cable. This could be caused by the fact the cable was relatively short.

Table-V: Effect of cable inclination to the first natural frequency for cable with diameter of $6 \mathbf{~ m m}$.

\begin{tabular}{cccc}
\hline $\mathrm{P}(\mathrm{kN})$ & $\alpha\left(^{\circ}\right)$ & $\mathrm{f}_{1}(\mathrm{~Hz})$ & $\Delta \mathrm{f}_{1}(\%)$ \\
\hline \multirow{2}{*}{0,5} & 30 & 18,714 & \multirow{2}{*}{0,22} \\
& 60 & 18,673 & \\
\hline \multirow{2}{*}{0,7} & 30 & 22,5575 & \multirow{2}{*}{1,52} \\
& 60 & 22,22 & \\
\hline \multirow{2}{*}{1} & 30 & 26,45875 & \multirow{2}{*}{2,18} \\
& 45 & 25,895 & \multirow{2}{*}{. }
\end{tabular}

Table-VI: Effect of cable inclination to the first natural frequency for cable with diameter of $8 \mathrm{~mm}$.

\begin{tabular}{cccc}
\hline $\mathrm{P}(\mathrm{kN})$ & $\alpha\left(^{\circ}\right)$ & $\mathrm{f}_{1}(\mathrm{~Hz})$ & $\Delta \mathrm{f}_{1}(\%)$ \\
\hline \multirow{2}{*}{0,5} & 30 & 17,903 & \multirow{2}{*}{0,45} \\
& 60 & 17,823 & \\
\hline \multirow{2}{*}{0,7} & 45 & 19,075 & \multirow{2}{*}{4,46} \\
& 60 & 18,261 & \\
\hline \multirow{2}{*}{1} & 30 & 22,508 & \multirow{2}{*}{2,03} \\
& 45 & 22,060 & \\
\hline
\end{tabular}

\section{E. Comparison of the First Natural Frequency from} Dynamic Test and the Theoretical Value

After evaluating the effect of impact location, operators, and cable inclination angles to the natural frequency, the results of dynamic tests were then compared with the theoretical value using (2). Table-VII and Table-VIII show the comparison of the first natural frequency obtain from dynamic test with the theoretical value for different cable diameter and different cable tension load.

Table-VII: Comparison of the first natural frequency for cable with diameter of $6 \mathbf{~ m m}$

\begin{tabular}{ccccc}
\hline $\begin{array}{c}\alpha \\
\left(^{\circ}\right)\end{array}$ & $\begin{array}{c}\mathrm{P} \\
(\mathrm{kN})\end{array}$ & $\begin{array}{c}\mathrm{f}_{1}(\mathrm{~Hz}) \\
\text { Theoretical }\end{array}$ & $\begin{array}{c}\mathrm{f}_{1}(\mathrm{~Hz}) \\
\text { Measured }\end{array}$ & $\begin{array}{c}\Delta \mathrm{f}_{1} \\
(\%)\end{array}$ \\
\hline \multirow{3}{*}{30} & 0,5 & 18,588 & 18,714 & 0,68 \\
& 0,7 & 21,955 & 22,558 & 2,74 \\
& 1 & 26,285 & 26,459 & 0,66 \\
\hline \multirow{3}{*}{45} & 0,5 & 18,588 & 18,593 & 0,02 \\
& 0,7 & 21,955 & 21,390 & $-2,57$ \\
& 1 & 26,285 & 25,895 & $-1,48$ \\
\hline \multirow{2}{*}{60} & 0,5 & 18,588 & 18,673 & 0,45 \\
& 0,7 & 21,955 & 22,220 & 1,21 \\
\hline
\end{tabular}

Table-VIII: Comparison of the first natural frequency for cable with diameter of $8 \mathbf{~ m m}$

\begin{tabular}{ccccc}
\hline $\begin{array}{c}\alpha \\
\left(^{\circ}\right)\end{array}$ & $\begin{array}{c}\mathrm{P} \\
(\mathrm{kN})\end{array}$ & $\begin{array}{c}\mathrm{f}_{1}(\mathrm{~Hz}) \\
\text { Theoretical }\end{array}$ & $\begin{array}{c}\mathrm{f}_{1}(\mathrm{~Hz}) \\
\text { Measured }\end{array}$ & $\Delta \mathrm{f}_{1}(\%)$ \\
\hline \multirow{3}{*}{30} & 0,5 & 15,184 & 17,903 & 17,90 \\
& 0,7 & 17,965 & 20,144 & 12,13 \\
& 1 & 21,472 & 22,508 & 4,82 \\
\hline \multirow{3}{*}{45} & 0,5 & 15,184 & 16,648 & 9,64 \\
& 0,7 & 17,965 & 19,075 & 6,18 \\
& 1 & 21,472 & 22,060 & 2,74 \\
\hline \multirow{2}{*}{60} & 0,5 & 15,184 & 17,823 & 17,38 \\
& 0,7 & 17,965 & 18,261 & 1,65 \\
& 1 & 21,472 & 20,059 & $-6,58$ \\
\hline
\end{tabular}

It can be seen from Table-VI and table-VII that the differences in the first natural frequency values are relatively small for cable with diameter of $6 \mathrm{~mm}$, but will increase for cable with diameter of $8 \mathrm{~mm}$. 


\section{F. Comparison of the Cable Tensile Force from Dynamic Test and the Actual Load}

The accuracy of (2) was investigated by comparing the theoretical values of cable tension force with the actual tension forces of the cable from the given load. Table-IX and Table-X show the comparison of the cable tension loads obtain from dynamic tests with the actual values for different cable diameter and different cable tension loads.

Table-IX: Comparison of cable tensile force for cable with diameter of $6 \mathbf{~ m m}$

\begin{tabular}{cccc}
\hline $\mathrm{f}_{\mathrm{n}}(\mathrm{Hz})$ & $\mathrm{P}(\mathrm{kN})$ & $\mathrm{P}(\mathrm{kN})$ & $\Delta \mathrm{P}(\%)$ \\
Measured & Measured & Actual & 0,8 \\
\hline 18,66 & 0,504 & 0,5 & 0,58 \\
22,056 & 0,704 & 0,7 & $-0,8$ \\
26,18 & 0,992 & 1 & \\
\hline
\end{tabular}

Table-X: Comparison of cable tension force for cable with diameter of $8 \mathrm{~mm}$

\begin{tabular}{cccc}
\hline $\mathrm{f}_{\mathrm{n}}(\mathrm{Hz})$ & $\mathrm{P}(\mathrm{kN})$ & $\mathrm{P}(\mathrm{kN})$ & \multirow{2}{*}{$\mathrm{P}(\%)$} \\
Measured & Measured & Actual & \\
\hline 17,458 & 0,661 & 0,5 & 32,2 \\
19,16 & 0,796 & 0,7 & 13,71 \\
21,542 & 1,006 & 1 & 0,6 \\
\hline
\end{tabular}

Table-IX shows that the accuracy of cable tension force from dynamic testing is relatively high for cable with diameter of $6 \mathrm{~mm}$. However, the accuracy is relatively low for cable with diameter of $8 \mathrm{~mm}$ as shown in Table-X. It is interesting to notice that the accuracy will increase as the applied load increases.

\section{G. Effect of the Strain Value to the Accuracy of the first Natural Frequency from Dynamic Test}

Table- $X$ indicates that the accuracy is affected by the magnitude of cable tension force. The cable's strain is directly related to the tensile force. The strain of be cable is presented in Table-XI and Table-XII for cable dimeter of 6 $\mathrm{mm}$ and $8 \mathrm{~mm}$ respectively.

Table-XI: Strain value of cable with diameter of $6 \mathbf{~ m m}$

\begin{tabular}{|c|c|c|c|}
\hline $\mathrm{L}(\mathrm{m})$ & $\begin{array}{l}\mathrm{P}(\mathrm{kN}) \\
\text { Actual }\end{array}$ & $\Delta \mathrm{L}(\mathrm{mm})$ & Strain $(\varepsilon)$ \\
\hline \multirow{3}{*}{1,41} & 0,5 & 0,151 & $8,84 \cdot 10^{-5}$ \\
\hline & 0,7 & 0,212 & $1,24.10^{-4}$ \\
\hline & 1 & 0,302 & $1,77.10^{-4}$ \\
\hline \multicolumn{4}{|c|}{ Table-XII: Strain value of cable diameter of $8 \mathrm{~mm}$} \\
\hline $\mathrm{L}(\mathrm{m})$ & $\begin{array}{l}\mathrm{P}(\mathrm{kN}) \\
\text { Actual }\end{array}$ & $\Delta \mathrm{L}(\mathrm{mm})$ & Strain $(\varepsilon)$ \\
\hline \multirow{3}{*}{1,41} & 0,5 & 0,085 & $4,97.10^{-5}$ \\
\hline & 0,7 & 0,119 & $6,96 \cdot 10^{-5}$ \\
\hline & 1 & 0,170 & $9,95.10^{-5}$ \\
\hline
\end{tabular}

From Table-VII, Table-VIII and Table-IX, the relationship between the strain value and the accuracy of the first natural frequency value from the dynamic test can be summarized and is presented in Fig. 9.

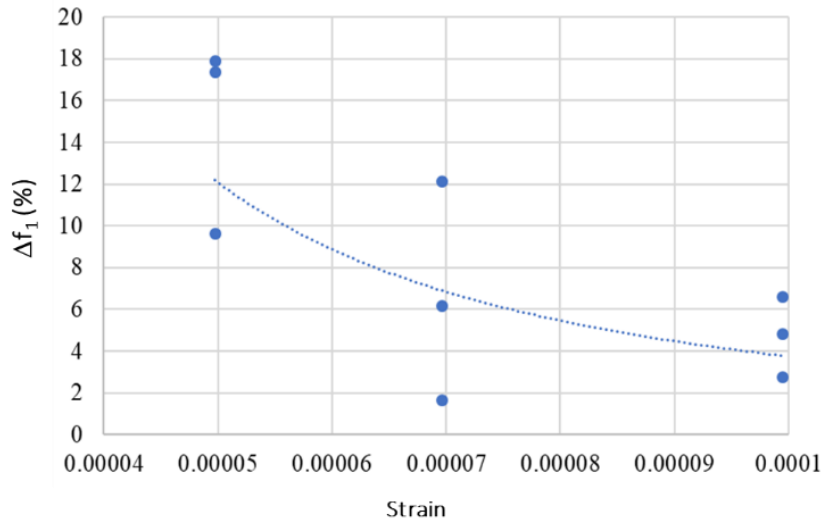

Fig. 9. Comparison of Strain with Natural Frequency

Fig. 9 shows that the higher the strain value, the more accurate the first natural frequency value obtain from the experiment. Therefore it can be concluded, theoretical formula will give more accurate value if the cable has higher strain.

\section{CONCLUSION AND RECOMENDATION}

Based on the results of this research, the following conclusions can be made:

a. The accelerometer's position, the locations of the impact and the variations of the operators had no effect on the test result;

b. The inclination of the cable does not significantly affect the level of consistency of the formula used to calculate the cable force;

c. The accuracy of the formula is affected by the strain of the cable.

d. The higher the strain, the more accurate the formula will be.

It is suggested that for the future research, the effect of the strain value and the slenderness should be taken into account.

\section{REFERENCES}

1. Y.H. Huang, J. Y. Fu, R. H. Wang, Q. Gan, R. Rao, and A. R. Liu, "Practical formula to calculate tension of vertical cable with hinged-fixed conditions based on vibration method", Journal of Vibro Engineering, Vol. 16, Issue 2, 2014, pp. 997-1009.

2. D. Feng, T. Scarangello, M. Q. Feng, and Q. Ye, "Cable tension force estimate using novel noncontact vision-based sensor. Measurement", Volume 99, 2017, pp. 44-52

3. M. Suangga, I. Hidayat, Juliastuti, Celine, "Temperature effect on cable tension forces of cable-stayed Bridge", IOP Conf. Series: Earth and Environmental Science 195, 2018.

4. B. H. Kim and T. Park, "Estimation of cable tension force using the frequency-based system identification method", Journal of Sound and Vibration, 304, 2007, pp. 660-676.

5. S. N. Debora, S. Parivallal, K. Ravisankar, and G. Hemalatha, "Evaluation of Cable Tension Using Vibration Based Methodologies for Health Monitoring of Structures”. IJIRSET,Vol.4, Special Issue 6, 2015, pp. 506-513

6. Z. Fang and J. Q. Wang, "Practical Formula for Cable Tension Estimation by Vibration Method", Journal of Bridge Engineering ASCE, Vol. 17, Issue 1, 2012, pp. 161-164.

7. B. H. Kim, T. Park, H. Shin and T. Y. Yoon, "A Comparative Study of the Tension Estimation Methods for Cable Supported Bridges", Steel Structures, 7, 2007, pp. 77-84. 


\section{AUTHORS PROFILE}

Made Suangga is a lecturer at Civil Engineering Department, Bina Nusantara University in Jakarta, Indonesia. He completed his undergraduate study at the Bandung Institute of Technology (1992), Master Program in Highway Engineering and System at the Bandung Institute of Technology (1995), and completed a doctoral program at Yokohama National University focusing on Wind and Bridge (2000)

Rayner Gunawan is completed his undergraduate study program at Bina Nusantara University (2018) with a focus on structural engineering

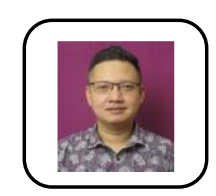

Irpan Hidayat is a lecturer at Civil Engineering Department, Bina Nusantara University in Jakarta, Indonesia. He completed his undergraduate study at the Bina Nusantara University (2005), Master Program in Structural Engineering at the University of Indonesia (2011), and continued his doctor's program at Tarumanagara University with a focus on structural engineering. 